\title{
Comparison of Two Models for Temperature Observation of Miniature PEM Fuel Cells Under Dry Conditions
}

Denise A. McKahn

Smith College,dmckahn@smith.edu

Xinyi Liu

Smith College

Follow this and additional works at: https://scholarworks.smith.edu/egr_facpubs

Part of the Engineering Commons

\section{Recommended Citation}

McKahn, Denise A. and Liu, Xinyi, "Comparison of Two Models for Temperature Observation of Miniature PEM Fuel Cells Under Dry Conditions" (2015). Engineering: Faculty Publications, Smith College, Northampton, MA.

https://scholarworks.smith.edu/egr_facpubs/6 


\title{
Comparison of Two Models for Temperature Observation of Miniature PEM Fuel Cells Under Dry Conditions
}

\author{
Denise A. McKahn Member, IEEE, and Xinyi Liu
}

\begin{abstract}
Water and thermal management have been identified as technical hurdles to the successful implementation of low temperature, polymer electrolyte membrane (PEM), fuel cell power systems. In low power applications, miniature PEM fuel cells show significant promise as a competitor to lithium-ion batteries. Significant design work is underway to improve the specific power and energy densities of these fuel cells. However, little attention has been given to characterizing transient response in these miniature applications to enable gains in system design, optimization and control. This work develops, calibrates and experimentally validates two different dynamic control-oriented models for open-loop temperature state observation in miniature PEM fuel cells. Of critical importance, these estimators target operation under dry conditions with no reactant pre-treatment. Operational conditions are then identified for which each model architecture is more suitable, specifically targeting minimal model complexity. A sensitivity analysis was completed that indicates necessary sensor measurements with sensor frugality in mind. The dynamic response under changes in load and fuel stoichiometry are well captured over a range of operating conditions.
\end{abstract}

Index Terms-fuel cell, dynamics, thermal, modeling, miniature.

\section{INTRODUCTION}

A polymer electrolyte membrane (PEM) fuel cell (PEMFC) stack is an electrochemical engine that combines hydrogen and oxygen to produce useful work. When fuel supply, humidification and cooling systems are well managed, fuel cell stacks provide clean, quiet and reliable power. The application of interest is unmanned lightweight aircraft, specifically on controlled meteorological balloons (CMETs) for atmospheric gas sampling at low altitude [1]. A lightweight aerial system must operate at relatively low power $(1-50 \mathrm{~W})$; have minimal total system mass; tolerate startup at ambient conditions; and operate at a high electrical efficiency. At low altitude and low power requirements, batteries are most commonly used [1]. The first fuel cell aircraft was announced in 2005 [2]. Since then, hybrid electric propulsion systems have included solid oxide [3] and PEMFC stacks [4] at power levels greater than $100 \mathrm{~W}$ for both short and long endurance flights.

Figure 1 displays the hardware architecture for lightweight miniature CMET applications. A rationale for the system

Manuscript received July 22, 2014; revised October 18, 2014, December 17, 2014 and March 20, 2015; accepted March 26, 2015.

Copyright (c) 2015 IEEE. Personal use of this material is permitted. However, permission to use this material for any other purposes must be obtained from the IEEE by sending a request to pubs-permissions@ieee.org.

Both authors are with the Picker Engineering Program, Smith College, Northampton, MA, 01063 USA (e-mail:dmckahn@smith.edu) architecture used for miniature PEMFC stacks in CMET applications is provided in [5]. An electrical load is applied to the stack which includes meteorological sensors, data acquisition and signal conditional electronics, as well as altitude control actuators. The PEMFC power system must be capable of providing 3.5 VDC at $1.5 \mathrm{~A}$ for a $15-\mathrm{hr}$ flight. The hardware consists of a low pressure balloon filled with dry hydrogen. Hydrogen flow is pressure regulated and the outlet is deadended. Ambient air is supplied by a blower or fan at either constant or stoichiometric flow.

To reduce mass, the gas humidification system is removed. The coolant system is removed due to the relatively small amount of waste heat at low power. While a miniature PEMFC system might now seem simple by comparison, product water is still multi-phase, exciting flooding and drying dynamics [6], [7], nitrogen diffusion still presents a challenge to anode purging strategies [8], waste heat must still be rejected, and net power output must still be maximized. These design and architecture choices have significant consequences on the observability and controllability of states that impact cell performance, and thus, the resultant control architecture. Simplifying the subsystems for miniaturization poses exciting new challenges to the optimization of specific power and energy density (W/g and $\mathrm{Wh} / \mathrm{g})$.

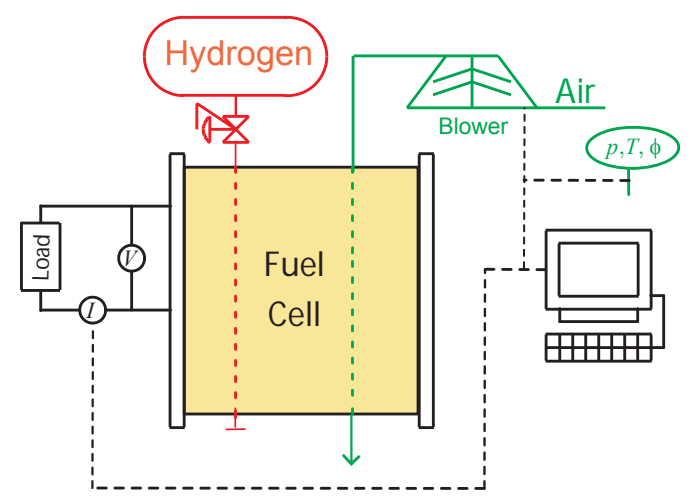

Fig. 1: Schematic diagram of PEMFC stack and subsystems for miniature lightweight applications. Signals are in dotted lines and plumbing connections are solid lines.

Several cooling strategies have been studied for a range of power outputs. Due to the high power density needs of automotive applications, internal liquid coolants are used [9], [10]. At moderate power densities, air can be forced 
through internal cooling plates. At low power, the stack can be passively cooled via free convection from the exterior to the ambient or through forced convection inside the cathode channels [11]. Design tradeoffs associated with these cooling strategies have been investigated for a range of applications [12].

Several control-oriented thermal models have lumped the cell materials into a single control volume to predict the membrane and exhaust gas temperatures for large PEMFC stacks that have significant thermal mass [13], [14]. For control, either the exhaust gas or the coolant outlet temperatures are used for output feedback. In those works, the anode and cathode exhaust temperatures, if predicted separately, are static linear functions of stack temperature. However, the mass and specific heat of the solid cell materials result in a significantly different thermal response time than the response associated with the relatively low mass of the reactant gases. These characterizations are adequate for capturing reactant dynamics that occur simultaneously with load transients. However, when the cathode supply gas is used for thermal regulation, the reactant and thermal dynamics must be independently actuated.

This distinction can not be overstated. To use reactant flow for active thermal management, models must capture the thermal response during changes in the air mass flow rate (fast thermal dynamics) separately from changes in the load (slow thermal dynamics). While [15] extended the control-oriented mass dynamics framework presented by [6], [16] to include a dynamic temperature state, the fuel cell stack remains a uniform single volume with respect to temperature.

Two dimensional (2D) and three dimensional (3D) steadystate models of mass transport have been developed that are non-isothermal along the channel [17]. With a comparable gas channel width, depth, and flow pattern, water activity and spatially distributed current density do not appreciably change across the first $14 \mathrm{~cm}$ of the channel length [17], which is twice the length of the miniature PEMFC stacks of interest. Thus, a $2 \mathrm{D}$ or $3 \mathrm{D}$ modeling approach may not be necessary to capture the thermal dynamics of interest for control applications in miniature PEMFC systems.

In this work, we modify the standard one control volume control-oriented model of thermal dynamics from [13] to account for dry conditions with no reactant humidification. A new model is then derived by adding a second cathode control volume. These models are experimentally calibrated and validated and measurement sensitivity is explored. These models can be deployed as open-loop observers of internal temperature states for thermal regulation specifically targeting miniature and low power PEMFC systems.

\section{NOMENCLATURE}

The modeling nomenclature is detailed in Table I. Subscripts denote a species or method, such that $a$ is dry air, $b$ is bulk materials, $c v$ is control volume, exc is excess, $\mathrm{H}_{2}$ is hydrogen, $\mathrm{H}_{2} \mathrm{O}$ is water, $l w$ is liquid water, $\mathrm{o}$ is standard state, $\mathrm{O}_{2}$ is oxygen, prod is product, $r c$ is reaction, $v$ is water vapor, and $w$ is water. Subscripts also indicate location, where $a m b$ is ambient, $a n$ is anode, $c a$ is cathode, in is into the control volume, and out is out of the control volume. The number 2 between subscripts indicates directional heat transfer, such as $b 2 a m b$ indicating transfer from the bulk to the ambient.

\section{TABLE I: MODEL NOMENCLATURE}

\begin{tabular}{llc} 
Parameter & Description & $\mathrm{Unit}$ \\
\hline \hline$A$ & surface area & $\mathrm{m}^{2}$ \\
$C$ & specific heat & $\mathrm{J} /(\mathrm{kg} \mathrm{K})$ \\
$F$ & Faraday's constant & $\mathrm{A} \mathrm{s}$ \\
$H$ & rate of enthalpy transfer & $\mathrm{W}$ \\
$h$ & convective heat transfer coefficient & $W /\left(m^{2} K\right)$ \\
$h_{f}^{0}$ & specific enthalpy of formation & $\mathrm{J} / \mathrm{kg}$ \\
$h_{f g}$ & specific enthalpy of evaporation & $\mathrm{J} / \mathrm{kg}$ \\
$I$ & current & $\mathrm{A}$ \\
$M$ & molecular mass & $\mathrm{kg} / \mathrm{mol}$ \\
$m$ & mass & $\mathrm{kg}$ \\
$\dot{m}$ & mass flow & $\mathrm{kg} / \mathrm{s}$ \\
$n$ & number of cells in the stack & $(-)$ \\
$\phi$ & relative humidity & $(-)$ \\
$P$ & electrical power & $\mathrm{W}$ \\
$p$ & total pressure & $\mathrm{Pa}$ \\
$p_{s a t}$ & water vapor saturation pressure & $\mathrm{Pa}$ \\
$Q$ & rate of heat transfer & $\mathrm{W}$ \\
$T$ & temperature & $\mathrm{K}$ \\
$t$ & time & $\mathrm{s}$ \\
$V$ & voltage & $\mathrm{V}$ \\
\hline
\end{tabular}

The acronyms $1 \mathrm{CV}$ and $2 \mathrm{CV}$ are used to describe one and two control volumes, CMET is controlled meteorological balloon, MEA is membrane electrode assembly, GDL is gas diffusion layer, PEM is polymer electrolyte membrane, and PEMFC is polymer electrolyte membrane fuel cell.

\section{MODEL DEVELOPMENT}

To generate state equations, conservation of energy is applied to a control volume. Assuming no changes in kinetic and potential energy and that stack materials remain solid, the change in internal energy, $U_{c v}$, is a function of temperature, $T_{c v}$, expressed as

$$
\frac{\partial U_{c v}}{\partial t} \approx m_{c v} C_{c v} \frac{d T_{c v}}{d t} .
$$

While water can accumulate in or be removed from the volume over time, given the small active area and relatively large gas channels [18], this water mass is negligible when compared to the cell mass. The greatest impact of water accumulation on thermal dynamics is associated with phase change, which is not neglected. We assume water vapor does not enter the stack with supplied reactants. This operational strategy is a significant deviation from the large stacks operated at high current density, and more aligned with operation in airbreathing systems [19]. The sensitivity of the temperature estimations to this modeling assumption is provided.

First, an existing single state model from [13] is modified to produce the ' $1 \mathrm{CV}$ ' model. The cathode control volume is then separated from the bulk control volume, adding temperature and water mass states, to capture the thermal response when load transients and gas dynamics do not occur simultaneously. This second model is referred to as the ' $2 \mathrm{CV}$ ' model. 


\section{A. One Control Volume Model}

In the $1 \mathrm{CV}$ model, cell materials are lumped into a single "bulk" volume comprised of the membrane electrode assembly (MEA), gas diffusion layers (GDL), flow channels that distribute constituents to and from manifolds to the GDL, and electrically conductive separator plates. Figure 2 shows the bulk temperature state, inlet and outlet mass flow rates, heat transfer losses, and inlet and outlet temperatures.

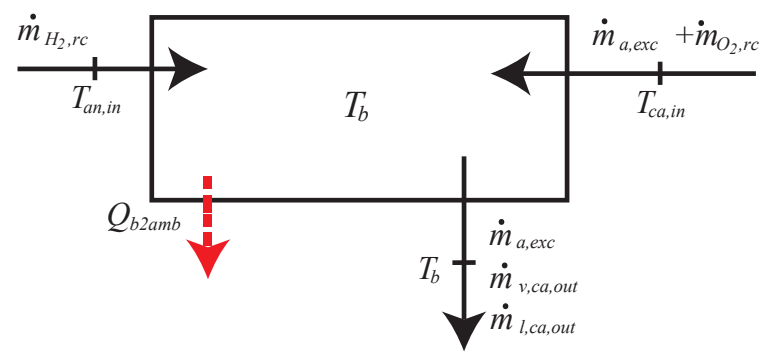

Fig. 2: Block diagram of the $1 \mathrm{CV}$ thermal model. Solid lines denote mass flow and Dashed lines indicate heat transfer.

Conservation of energy on the bulk materials results in

$$
\frac{d T_{b}}{d t}=\frac{1}{m_{b} C_{b}}\left[H_{r c}+\Delta H_{a}+\Delta H_{w}-Q_{b 2 a m b}-P\right],
$$

where $m_{b}$ is the mass of the bulk, $C_{b}$ is the specific heat of the bulk materials, $T_{b}$ is the bulk temperature, $H_{r c}$ is the heat of reaction, $\Delta H_{a}$ and $\Delta H_{w}$ are the enthalpy differences associated with the input and output dry air and water mass flow rates, respectively, $Q_{b 2 a m b}$ is the convective heat loss from the bulk to the ambient, and $P$ is the electrical power produced by the fuel cell. Power is an input to the model but a physical power output from the stack.

The heat of reaction is defined as

$$
\begin{aligned}
H_{r c}= & \dot{m}_{H_{2}, r c}\left(h_{f, H_{2}}^{o}+C_{p, H_{2}}\left(T_{a n, i n}-T_{o}\right)\right) \\
& +\dot{m}_{O_{2}, r c}\left(h_{f, O_{2}}^{o}+C_{p, O_{2}}\left(T_{c a, i n}-T_{o}\right)\right) \\
& -\dot{m}_{l w, p r o d}\left(h_{f, l w}^{o}+C_{p, l w}\left(T_{b}-T_{o}\right)\right),
\end{aligned}
$$

with

$$
\dot{m}_{i}=M_{i} n \frac{I}{j F},
$$

where in (4) the subscript $i$ denotes the constituent (hydrogen, oxygen or water) and $j$ is an index for the stoichiometric fraction $j \in[2,4,2]$, respectively, $T_{c a, i n}$ and $T_{a n, i n}$ are the cathode and anode inlet temperatures, and $T_{o}$ is the standard reference temperature.

The air enthalpy difference is modeled by

$$
\Delta H_{a}=\dot{m}_{a, e x c} C_{p, a}\left(T_{c a, i n}-T_{b}\right),
$$

where the excess air mass flow rate is described by

$$
\dot{m}_{a, e x c}=\dot{m}_{a, c a, i n}-\dot{m}_{O_{2}, r c} .
$$

The enthalpy associated with the oxygen consumed in the reaction is taken at the cathode inlet temperature in (3). As a result, the change in enthalpy of the air is applied only to the excess air. Because the cathode, where the reaction takes place, is lumped with the bulk, the air acts as flow over a hot plate. Thus, the cathode exhaust is in thermal equilibrium with the bulk and leaves the cathode at the bulk temperature state.

The change in enthalpy of the water is described by

$$
\Delta H_{w}=-\dot{m}_{l w, p r o d} C_{p, l w}\left(T_{b}-T_{o}\right)-\dot{m}_{v, c a, o u t} h_{f g, T_{b}},
$$

where $\dot{m}_{l w, p r o d}$ is the liquid water production rate for the reaction in (4), $\dot{m}_{v, c a, \text { out }}$ is the water vapor mass flow leaving the bulk at the cathode outlet, and $h_{f g, T_{b}}$ is the enthalpy of evaporation evaluated at the bulk temperature state. Here, water does not accumulate within the cathode volume. As a result, the amount of liquid water leaving the cathode is equal to the difference between the liquid water produced, $\dot{m}_{l w, p r o d}$, and the water vapor leaving the cathode, $\dot{m}_{v, \text { ca,out }}$, resulting in the rearranged form shown in (7).

Deploying psychrometric properties, the mass flow rate of water vapor leaving the cathode is expressed as

$$
\dot{m}_{v, \text { ca }, \text { out }}=\frac{\dot{m}_{a, e x c} M_{w} \phi_{c a, \text { out }} p_{\text {sat }, T_{b}}}{M_{a}\left(p_{\text {ca,out }}-\phi_{c a, \text { out }} p_{\text {sat }, T_{b}}\right)} .
$$

Measurement of exhaust gas relative humidity is not trivial and increases cost and weight. As a result, the relative humidity of the air leaving the cathode is first calculated as if all liquid water produced were to evaporate,

$$
\phi_{c a, \text { out }}=\frac{\dot{m}_{l w, p r o d} M_{a} p_{c a, o u t}}{p_{\text {sat }, T_{b}}\left(\dot{m}_{a, \text { exc }} M_{w}+\dot{m}_{l w, p r o d} M_{a}\right)} .
$$

If $\phi_{c a, \text { out }}>1$, the air leaving the cathode is saturated and $\phi_{c a, \text { out }}=1$ in (8). If $\phi_{c a, \text { out }}<1$, all product water evaporates and leaves the cathode such that $\dot{m}_{v, \text { ca,out }}=\dot{m}_{l w, p r o d}$. This assumption is distinct from the $2 \mathrm{CV}$ model by not allowing water to accumulate within the cathode.

The specific enthalpy of evaporation, $h_{f g}$, and the water vapor saturation pressure, $p_{s a t, T}$, are tabulated in [20]. By performing a least squares minimization of the difference between the tabulated and estimated variable, both the specific enthalpy and water vapor saturation pressure, $p_{s a t, T}$, are expressed as a function of water temperature, $T$,

$$
\begin{aligned}
h_{f g, T}= & 3159837-2394.3 T, \\
p_{\text {sat }, T}= & 0.0006853 T^{4}-0.7432 T^{3}+304.1 T^{2} \\
& -55614 T+3.8318 .
\end{aligned}
$$

Due to low cathode total pressures of less than $3 \mathrm{kPa}$ gauge, the enthalpy of the water is modeled as a saturated vapor mixture.

Heat is lost to the environment through convection and radiation. A sensitivity analysis on the influence of bulk emissivity on estimated cathode outlet temperature resulted in a sensitivity of less than 5\%. As a result, radiative heat transport has been neglected. The convective heat loss from the bulk to the ambient, $Q_{b 2 a m b}$, is modeled by

$$
Q_{b 2 a m b}=h_{b 2 a m b} A_{b 2 a m b}\left(T_{b}-T_{a m b}\right) .
$$

The convective heat transfer coefficient depends on the medium properties, flow, and surface geometry and will be experimentally identified.

The power produced by the stack is calculated by

$$
P=I V .
$$


Because the cathode outlet is assumed to be in thermal equilibrium with the bulk materials, the model output is the cathode outlet temperature, such that

$$
T_{\text {ca,out }}=T_{b} \text {. }
$$

In summary, the one control volume model has one state, $T_{b}$; a control input of $\dot{m}_{a, c a, i n}$; measurement inputs of $V$ and $p_{c a, \text { out }}$; measured disturbances from $T_{a m b}, I, T_{c a, i n}$, and $T_{a n, i n}$; with an output of the cathode outlet temperature $T_{\text {ca,out }}$. While it may appear as though the system is higher order due to the use of standard thermodynamic nomenclature to denote mass flow as $\dot{m}$, these are measured or calculated known values that depend on the inputs and are not states.

\section{B. Two Control Volume Model}

In extending from $1 \mathrm{CV}$ to $2 \mathrm{CV}$, water is allowed to accumulate with minimal model complexity compared to the significantly higher order isothermal [6], [8], [16] and nonisothermal [15] dynamic models. Because these models are intended for thermal management, and not the management of water or reactants, the more detailed full mass dynamics can be simplified. Second, we separate the cathode thermal and air mass dynamics to capture the impact of changes in air mass flow on the thermal dynamics. In this cathode volume, dry air is supplied and oxygen is transferred to the bulk where the chemical reaction occurs. Product water returns to the cathode, and the excess gases leave the volume as shown in Figure 3.

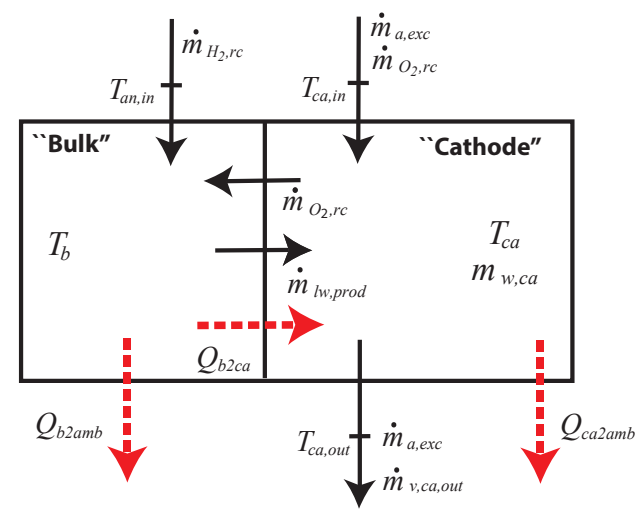

Fig. 3: Block diagram of the $2 \mathrm{CV}$ thermal model. Solid lines denote mass flow and dashed lines indicate a transfer of heat.

Conservation of energy is applied to each control volume. Energy transfers associated with mass, heat, and electrical work result in the two state equations

$$
\begin{aligned}
\frac{d T_{b}}{d t} & =\frac{1}{m_{b} C_{b}}\left[H_{r c}-Q_{b 2 a m b}-Q_{b 2 c a}-P\right] \\
\frac{d T_{c a}}{d t} & =\frac{1}{m_{c a} C_{c a}}\left[\Delta H_{a}+\Delta H_{w}+Q_{b 2 c a}-Q_{c a 2 a m b}\right] .
\end{aligned}
$$

In (14a), the rate of change of energy in the bulk is equal to the heat of reaction less the losses associated with heat exchange to the ambient, $Q_{b 2 a m b}$, cathode, $Q_{b 2 c a}$, and the rate of electric power produced, $P$. In (14b), the rate of change of energy in the cathode is equal to the sum of enthalpy flow rates associated with the air, $\Delta H_{a}$ and water, $\Delta H_{w}$, and the rate of heat transferred from the bulk to the cathode less the heat loss from the cathode to the ambient, $Q_{c a 2 a m b}$.

With an added control volume, the deviation in the oxygen specific enthalpy has a different temperature reference than that expressed in (3), resulting in

$$
\begin{aligned}
H_{r c}= & \dot{m}_{H_{2}, r c}\left(h_{f, H_{2}}^{o}+C_{p, H_{2}}\left(T_{a n, i n}-T_{o}\right)\right) \\
& +\dot{m}_{O_{2}, r c}\left(h_{f, O_{2}}^{o}+C_{p, O_{2}}\left(T_{c a}-T_{o}\right)\right) \\
& -\dot{m}_{l w, p r o d}\left(h_{f, l w}^{o}+C_{p, l w}\left(T_{b}-T_{o}\right)\right) .
\end{aligned}
$$

Mass flow rates are unchanged from (4).

The convective heat transfer from the bulk to the ambient, $Q_{b 2 a m b}$, is described in (11) and the electrical power produced by the stack is described in (12). The heat transfer from the bulk to the cathode and from the cathode to the ambient are

$$
\begin{aligned}
Q_{c a 2 a m b} & =h_{c a 2 a m b} A_{c a 2 a m b}\left(T_{c a}-T_{a m b}\right), \\
Q_{b 2 c a} & =h_{b 2 c a} A_{b 2 c a}\left(T_{b}-T_{c a}\right) .
\end{aligned}
$$

In calculating the change in enthalpy of the air in the cathode, $\Delta H_{a}$, the cathode exhaust reference temperature is different than in (5), such that

$$
\Delta H_{a}=\dot{m}_{a, \text { exc }} C_{p, a}\left(T_{c a, \text { in }}-T_{c a, \text { out }}\right),
$$

where the excess air mass flow rate is detailed in (6).

Water vapor enters and exits the cathode at different temperatures, with an associated difference in enthalpy, $\Delta H_{w}$,

$$
\begin{aligned}
\Delta H_{w}= & \dot{m}_{w, \text { prod }} C_{p, l w}\left(T_{b}-T_{o}\right) \\
& -\dot{m}_{v, \text { ca }, \text { out }}\left[C_{p, l w}\left(T_{c a, \text { out }}-T_{o}\right)+h_{f g, T_{c a, \text { out }}}\right] .
\end{aligned}
$$

The clear distinction between the $1 \mathrm{CV}$ and the $2 \mathrm{CV}$ models is the added cathode water mass state, $m_{w, c a}(\mathrm{~kg})$, shown by

$$
\frac{d m_{w, c a}}{d t}=\dot{m}_{w, p r o d}-\dot{m}_{v, c a, \text { out }} \text {. }
$$

Here, liquid phase water does not leave the cathode, and is assumed to have an insignificant impact on the cathode total pressure or the mass of air within the cathode.

Assuming that the relative humidity of the gas leaving the cathode is equal to that in the cathode, the cathode relative humidity is now a function of the mass of water accumulating in the cathode volume, shown by

$$
\phi_{c a, \text { out }}=\frac{m_{w, c a} M_{a} p_{c a, \text { out }}}{p_{\text {sat }, T_{c a, \text { out }}}\left(m_{a, \text { ca }} M_{w}+\dot{m}_{w, c a} M_{a}\right)},
$$

where $m_{a, c a}$ is the mass of air in the cathode.

As with the $1 \mathrm{CV}$ model, an output equation is needed to relate the states to the measurable cathode outlet temperature, $T_{\text {ca,out }}$. While temperature sensors have been carefully embedded through-plane and along the channel to elicit important relations between material properties and operating conditions [21], this temperature sensor network is not practical for onboard thermal management. For control [22], it is assumed that the cathode temperature is a linear function of the inlet and outlet temperature,

$$
T_{c a, o u t}=2 T_{c a}-T_{c a, i n} .
$$


In summary, the $2 \mathrm{CV}$ model has three states, $T_{b}, T_{c a}$ and $m_{w, c a}$; a control input of $\dot{m}_{a, c a, i n}$; measurement inputs of $V$ and $p_{c a, o u t}$; measurable disturbances from $T_{a m b}, I, T_{c a, i n}$, and $T_{a n, i n}$; and an output of $T_{c a, o u t}$. While the inputs and disturbances do not differ from the $1 \mathrm{CV}$ model, the $2 \mathrm{CV}$ model has three states as opposed to the single state in the $1 \mathrm{CV}$ model and an additional input to the model output equation.

\section{PARAMETER IDENTIFICATION}

There are three categories of parameters: "look-up values" from known physical properties; calibrated values determined offline from physical measurements or material properties; and experimentally identified tunable parameters. Look-up values and calibrated parameters are shown in Table II.

TABLE II: KNOWN AND CALIBRATED PARAMETER VALUES

(a) FC independent parameters

\begin{tabular}{lcl} 
Parameter & Value & Unit \\
\hline \hline$C_{p, a}$ & 1004 & $\mathrm{~J} /(\mathrm{kg} \mathrm{K})$ \\
$C_{p, l w}$ & 4180 & $\mathrm{~J} /(\mathrm{kg} \mathrm{K})$ \\
$C_{p, H_{2}}$ & 14209 & $\mathrm{~J} /(\mathrm{kg} \mathrm{K})$ \\
$C_{p, O_{2}}$ & 922 & $\mathrm{~J} /(\mathrm{kg} \mathrm{K})$ \\
$M_{w}$ & 0.01802 & $\mathrm{~kg} / \mathrm{mol}$ \\
$M_{H_{2}}$ & 0.002016 & $\mathrm{~kg} / \mathrm{mol}$ \\
$M_{O_{2}}$ & 0.031999 & $\mathrm{~kg} / \mathrm{mol}$ \\
$M_{a}$ & 0.02897 & $\mathrm{~kg} / \mathrm{mol}$ \\
$F$ & 96485 & $\mathrm{C} / \mathrm{mol} \mathrm{e}^{-}$ \\
$\sigma$ & $5.67 * 10^{-8}$ & $\mathrm{~W} /\left(\mathrm{m}^{2} \mathrm{~K}^{4}\right)$ \\
$h_{f, H_{2}}^{0}, h_{f, O_{2}}^{0}$ & 0 & $\mathrm{~J} / \mathrm{kg}$ \\
$h_{f, l w}^{0}$ & -15866223 & $\mathrm{~J} / \mathrm{kg}$ \\
$T_{o}$ & 273.15 & $\mathrm{~K}$ \\
\hline
\end{tabular}

(b) FC dependent parameters, $1 \mathrm{CV}$ model.

\begin{tabular}{lcc} 
Parameter & Value & Unit \\
\hline \hline$n$ & 1 & cell \\
$m_{b}$ & $4.8 * 10^{-2}$ & $\mathrm{~kg}$ \\
$C_{b}$ & 1222 & $\mathrm{~J} /(\mathrm{kg} \mathrm{K})$ \\
$A_{b 2 a m b}$ & 0.008258 & $m^{2}$ \\
\hline
\end{tabular}

(c) FC dependent parameters, $2 \mathrm{CV}$ model.

\begin{tabular}{lcc} 
Parameter & Value & Unit \\
\hline \hline$n$ & 1 & cell \\
$m_{a, c a}$ & $2.75 * 10^{-6}$ & $\mathrm{~kg}$ \\
$m_{b}$ & $3.72 * 10^{-2}$ & $\mathrm{~kg}$ \\
$m_{c a}$ & $1.08 * 10^{-2}$ & $\mathrm{~kg}$ \\
$C_{b}$ & 1364 & $\mathrm{~J} /(\mathrm{kg} \mathrm{K})$ \\
$C_{c a}$ & 702 & $\mathrm{~J} /(\mathrm{kg} \mathrm{K})$ \\
$A_{b 2 a m b}$ & $3.34 * 10^{-3}$ & $m^{2}$ \\
$A_{c a 2 a m b}$ & $6.14 * 10^{-4}$ & $m^{2}$ \\
$A_{b 2 c a}$ & $4.67 * 10^{-3}$ & $m^{2}$ \\
\hline
\end{tabular}

In the $1 \mathrm{CV}$ model, the surface area between the bulk and ambient, $A_{b 2 a m b}$, was the total external surface area of the PEMFC. In the $2 \mathrm{CV}$ model, the surface area between the cathode and ambient, $A_{c a 2 a m b}$, was the external surface area of the cathode flow field with the remaining external surface area of the fuel cell stack attributed to $A_{b 2 a m b}$. The surface area between the bulk and the cathode, $A_{b 2 c a}$, was the surface area of the two cathode flow field faces.
The bulk mass, $m_{b}$, in the $1 \mathrm{CV}$ model was determined by weighing each of the fuel cell components. The mass of the cathode, $m_{c a}$, was calculated as the dry mass of the cathode flow field. Air in the cathode was assumed to be ideal with constant mass, $m_{a, c a}$, at the cathode inlet total pressure. The specific heat of the bulk materials was calculated from the mass averaged known specific heats of the cell materials.

The remaining parameters are tunable heat transfer coefficients. The following subsections provide a detailed description of the experimental identification process and results.

\section{A. Experimental Hardware}

A detailed analysis of the cell design, material choices, and hardware architecture for miniature CMET applications is in [5], [18]. While the voltage needs of the CMET are greater than a single cell PEMFC stack can provide, parallel work is considering a step up DC/DC converter, as deployed by other authors in [23], [24], [25], to reduce stack mass. As a result, a single cell PEMFC stack is deployed here. The cell utilizes a Nafion ${ }^{\circledR} 212$ MEA purchased from Ion Power, with an active area of $4.84 \mathrm{~cm}^{2}$, and a catalyst layer of $0.3 \mathrm{mg} / \mathrm{cm}^{2} \mathrm{Pt} / \mathrm{C}$. This active area was sized to meet the load demands for CMETs. A non-woven SGL Sigracet 10BC gas diffusion layer was chosen. The flow fields were made from $3.18 \mathrm{~mm}$ GM10 grade Graphtek graphite with straight parallel channels that are $1.17 \mathrm{~mm}$ wide and deep. In hardware implementation throughout this work, the terminology 'stack' is used to indicate this single cell fuel cell stack.

For identification and validation, test bench sensors and actuators were placed to mimic those in flight. In the CMET application, one can choose to measure all observer inputs. There is, of course, a mass penalty associated with added measurements. Observer inputs include stack voltage and current, cathode inlet temperature (ambient temperature), cathode inlet dry air mass flow and relative humidity, as well as the cathode outlet total pressure. Depending upon the flight campaign and the meteorological measurements that will be taken, some of these inputs may be measured [1]. By deploying a fuel cell power system, the additional input measurements to the CMET microcontroller are the fuel cell stack current and voltage.

The dry air and hydrogen supplied to the stack is in thermal equilibrium with the ambient, $T_{a m b}$, and was used as the cathode and anode inlet temperatures, $T_{c a, i n}$ and $T_{a n, i n}$, as would be assumed in flight. The current is a measurable disturbance. However, during the experiment both the current and the air mass flow rate are controlled and measured. The structure of the state estimators is shown in Figure 4.

The test bench hardware differs from the hardware in flight, shown in Figure 1, by providing more precise instrumentation. For example, air is delivered with a mass flow controller as opposed to a blower. A programmable electronic load is used to emulate in-flight load conditions.

Sensor specifications are provided in Table III. Signals are amplified using 5B Series signal conditioning modules with 4 $\mathrm{Hz}$ filters, and processed using a National Instruments USB6212 multifunction data acquisition board. Two analog outputs 

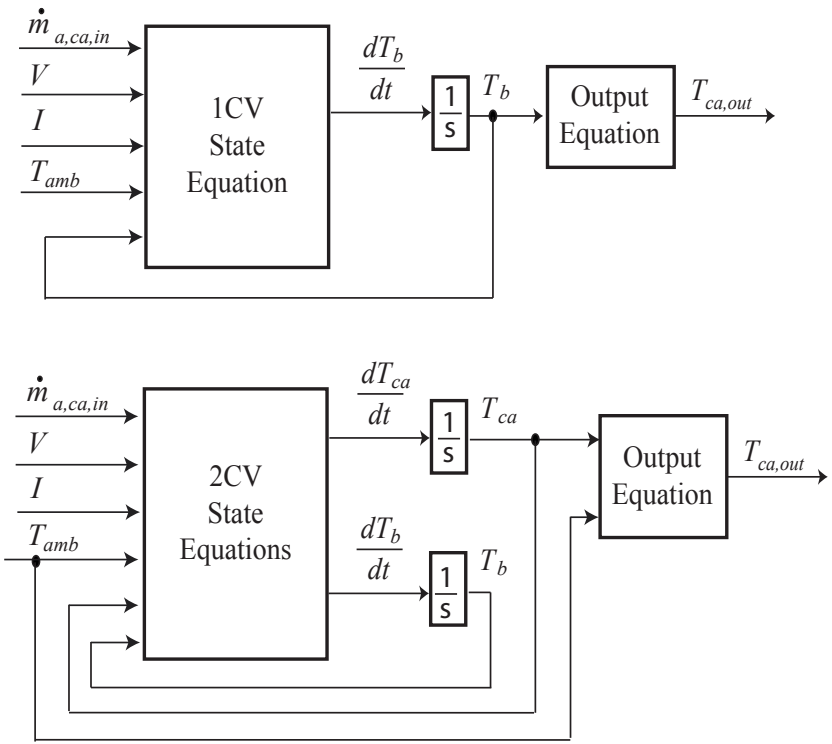

Fig. 4: Block diagram of the implemented open-loop temperature observer models indicating the measured inputs, estimated states and cathode outlet temperature output.

are used to control the electronic load as well as the air mass flow rate. There is significant bandwidth separation between the sampling rate and the modeled dynamics; therefore, realtime control and monitoring is not necessary in this application. Measurement accuracy is a manufacturer specification and addresses errors associated with linearity, hysteresis, thermal errors and repeatability, as well as the accuracy of the data acquisition system. In the case of the thermocouples, the accuracy specified is generated after instrument calibration with a known standard. Measurement noise was found to be normally distributed for all measurements except the air mass flow rate, with a standard deviation listed in Table III as $\sigma$.

\section{TABLE III: SENSOR SPECIFICATIONS}

\begin{tabular}{lcc} 
Sensor & Range and Accuracy & $\sigma$ \\
\hline \hline MFC MKS Type 1259C & $0-1000 \mathrm{sccm} \pm 10 \mathrm{sccm}$ & $0.48 \mathrm{sccm}$ \\
Omega Type T thermocouples & $\pm 0.1^{\circ} \mathrm{C}$ & $0.02^{\circ} \mathrm{C}$ \\
Ram Meter A5A50 shunt & $0-5 \mathrm{~A} \pm 17 \mathrm{~mA}$ & $0.7 \mathrm{~mA}$ \\
Voltage & $0-5 \mathrm{~V} \pm 0.15 \mathrm{mV}$ & $0.18 \mathrm{mV}$ \\
\hline
\end{tabular}

A dynamic testing protocol was established for the miniature PEMFC stack. Polarization curves were taken to emulate CMET accent and decent maneuvers and constant current operation emulates fixed altitude and sensor loads. The stack was operated at constant current densities of $60 \mathrm{~mA} / \mathrm{cm}^{2}$, $80 \mathrm{~mA} / \mathrm{cm}^{2}, 140 \mathrm{~mA} / \mathrm{cm}^{2}$, and $200 \mathrm{~mA} / \mathrm{cm}^{2}$ at a range of air mass flow rates. These current and air mass flow rates are within the range anticipated in flight. Throughout the experiment, ambient temperature rose from $23^{\circ} \mathrm{C}$ to $27^{\circ} \mathrm{C}$. In flight, the ambient temperature can deviate from $24^{\circ} \mathrm{C}-49^{\circ} \mathrm{C}$.

\section{B. Parameter Identification Process}

Heat transfer coefficients were identified over $n$ data points using least squares minimization of the cost function

$$
J=\frac{1}{n} \sum_{i=1}^{n}\left(\hat{T}_{c a, \text { out }}-\bar{T}_{\text {ca,out }}\right)^{2}
$$

to minimize the sum of the squared residuals in the measured, $\bar{T}_{c a, \text { out }}$ and estimated, $\hat{T}_{c a, \text { out }}$, cathode outlet temperatures.

Given the wide range of air mass flow rates supplied to the fuel cell stack during flight, convective heat transport depends on the materials and geometry over which heat is transported as well as the magnitude of the fluid velocity. Given a fixed geometry once the fuel cell stack is assembled and deployed, the convective heat transfer coefficients can then be related to the fluid mass flow rate.

Portions of the data set with constant air mass flow and dynamic current were selected. Then, constant convective heat transfer coefficients were identified by minimizing (23) during these portions of data at constant air flow. By plotting the "constant" heat transfer coefficients as a function of the air mass flow rate a nonlinear relationship was observed and fit with a second-order polynomial to capture forced and free convection, as described by

$$
h=\gamma_{1} \dot{m}_{a, c a, i n}^{2}+\gamma_{2} \dot{m}_{a, c a, i n}+\gamma_{3} .
$$

A least squares minimization of the difference between the identified and estimated heat transfer coefficients was made to identify the $\gamma$ parameters.

\section{Parameter Identification Results}

The identified convective heat transfer coefficients that relate to (24) are provided in Table IV. The resultant range in the convective heat transfer coefficients is $0.05-714 \mathrm{~W} / \mathrm{m}^{2} \mathrm{~K}$ over the experiment conducted. All heat transfer coefficients have expected values for heat transfer from a solid material to a gas through either forced or free convection.

TABLE IV: IDENTIFIED CONVECTIVE HEAT TRANSFER COEFFICIENTS

\begin{tabular}{l|l|c|c|c} 
& Model & $\gamma_{1}$ & $\gamma_{2}$ & $\gamma_{3}$ \\
\hline \hline$h_{b 2 a m b}$ & $1 \mathrm{CV}$ & $1.20 \cdot 10^{12}$ & $-5.19 \cdot 10^{5}$ & 28.4 \\
\hline \hline$h_{b 2 a m b}$ & $2 \mathrm{CV}$ & $9.07 \cdot 10^{11}$ & $-7.53 \cdot 10^{6}$ & 12.5 \\
\hline$h_{c a 2 a m b}$ & $2 \mathrm{CV}$ & $-1.81 \cdot 10^{13}$ & $1.00 \cdot 10^{8}$ & 170.3 \\
\hline$h_{b 2 c a}$ & $2 \mathrm{CV}$ & $-1.57 \cdot 10^{11}$ & $1.12 \cdot 10^{7}$ & 8.1 \\
\hline
\end{tabular}

Figure 5 compares the measured and estimated cathode outlet temperatures for both the $1 \mathrm{CV}$ and the $2 \mathrm{CV}$ state estimators during the entire test period. For the $2 \mathrm{CV}$ estimator the maximum difference between the measured and estimated cathode outlet temperature was $1.19^{\circ} \mathrm{C}$ with a mean difference of $0.27^{\circ} \mathrm{C}$ and a standard deviation of $0.38^{\circ} \mathrm{C}$. For the $1 \mathrm{CV}$ model the maximum difference between the measured and estimated cathode outlet temperature was $1.18^{\circ} \mathrm{C}$ with a mean difference of $0.26^{\circ} \mathrm{C}$ and a standard deviation of $0.37^{\circ} \mathrm{C}$. By simply comparing the descriptive statistics, which are 

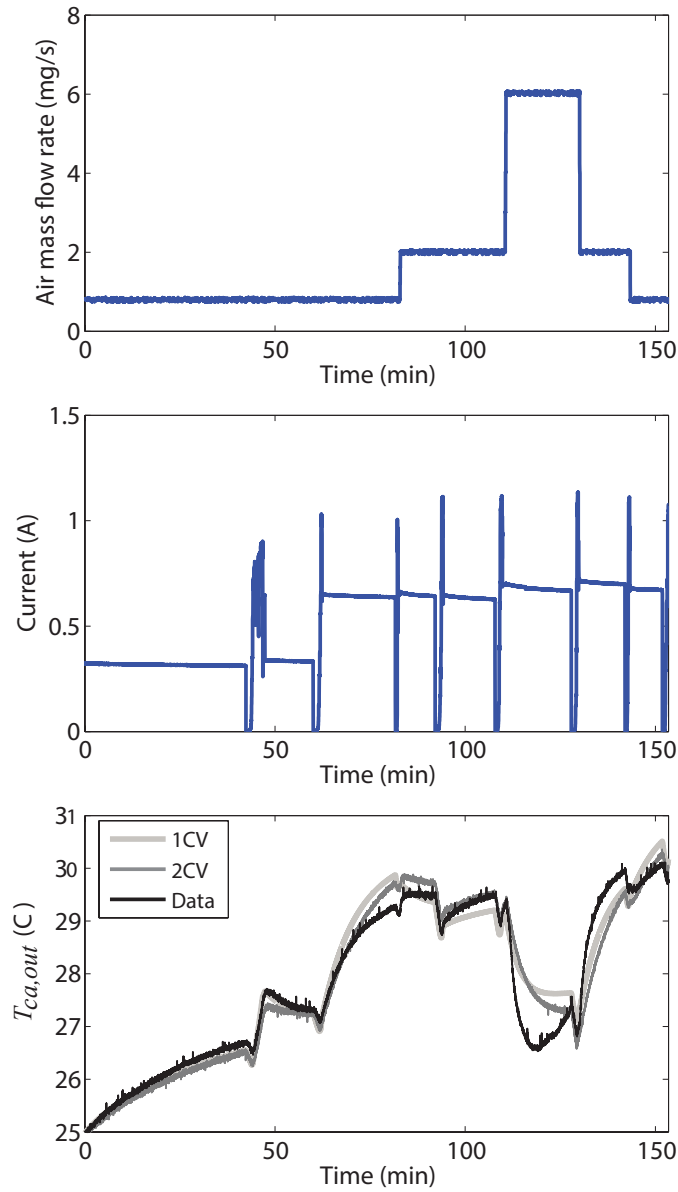

Fig. 5: Comparison of $1 \mathrm{CV}$ and $2 \mathrm{CV}$ state estimators against measured cathode air outlet temperature. Subplots are ordered as the measured input air mass flow rate, the measured fuel cell current disturbance, and the cathode outlet temperatures.

calculated over the entire data set, the difference between these state estimators is not significant.

Consider first the cathode outlet temperature response to disturbances induced by only a change in the fuel cell load at around 45 minutes. The air mass flow rate supplied is held constant. Because the energy source to the bulk materials is associated with the exothermic chemical reaction, the cathode outlet temperature follows the load applied to the fuel cell. When the fuel cell load is taken to open-circuit (no current is produced), the cathode outlet temperature decreases. When the electrical load is reapplied, the cathode outlet temperature increases. Both thermal models well capture load dynamics at constant air flow. As a result, if the cathode will be operated at a constant air mass flow rate throughout the flight, a $1 \mathrm{CV}$ state estimator is adequate for thermal management and the higher order state estimators are not justified.

Of greater interest is the ability to capture changes in the air mass flow rate independent from changes in load applied to the fuel cell. The observed excursions in cathode outlet temperature are not straightforward. There are times, such as near 83 minutes, when an increase in air mass flow results in an increase in the cathode outlet temperature. There are other times, such as near 110 minutes, when an increase in air mass flow results in a decrease in the cathode outlet temperature. The largest deviation in the cathode outlet temperature estimation takes place following a significant increase in air mass flow. While both estimators correctly predict the direction of the temperature excursion at this time, and reasonably approximate the quasi steady-state response, unmodeled evaporative cooling may be further reducing cathode temperature at this high air flow. It is important to note that this deviation represents a substantial increase in air mass flow rate and significantly high air excess ratios that are targeted at emulating the thermal regulation potential in using air excess for convective heat loss from the cathode. Figure 6 provides a closer inspection of the model estimates shown in Figure 5, focusing on changes in the fuel cell load, followed by a step change in the air mass flow rate supplied to the cathode.
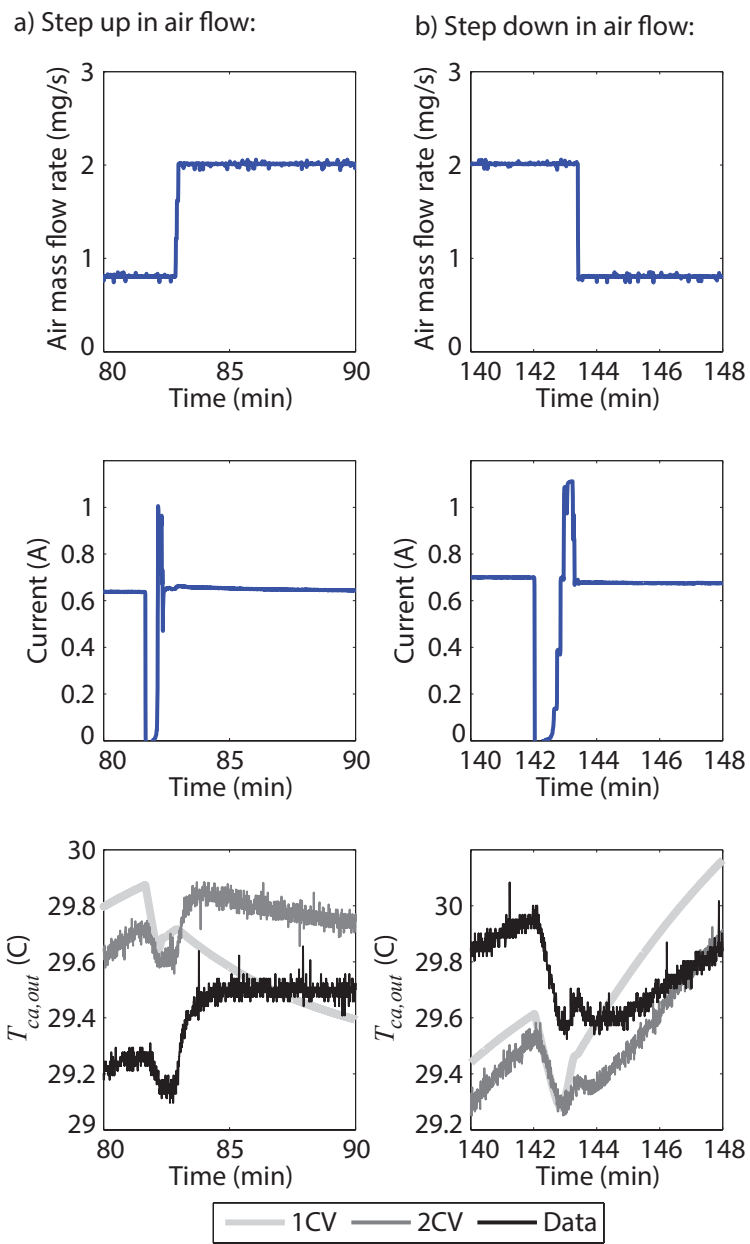

Fig. 6: Close inspection of the $1 \mathrm{CV}$ and the $2 \mathrm{CV}$ output estimation, from Figure 5, directly following a change in load and then air mass flow.

While both the $1 \mathrm{CV}$ and $2 \mathrm{CV}$ state estimators adequately capture the cathode outlet temperature response to the changes in load at both 82 minutes (column a) and 142 minutes (column b), the subsequent change in the air mass flow control input are not well captured by the $1 \mathrm{CV}$ model. For both a step up and a step down in air flow, the $1 \mathrm{CV}$ estimator predicts a temperature change in the wrong direction. For all step changes in the air mass flow rate, the $2 \mathrm{CV}$ state estimator correctly predicts the directional change in the cathode outlet 
temperature and adequately captures the magnitude of the response. If the cathode air mass flow rate will be used as a control input for thermal management, as opposed to simply acting as a disturbance that follows the fuel cell load, the $2 \mathrm{CV}$ state estimator should be used.

To explore the output sensitivity to measurement inaccuracy, a sensitivity analysis was conducted. For each measured input, the state trajectories were simulated by injecting measurement noise equal in magnitude to the sensor accuracy listed in Table III. Noise was first added and then subtracted from the nominal value, resulting in a total of eight simulated state trajectories.

a) Entire data set

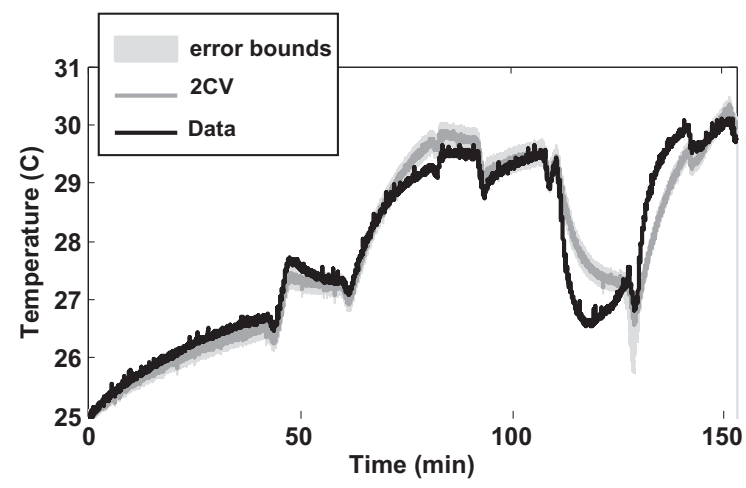

b) During step up in air flow:

c) During step down in air flow:
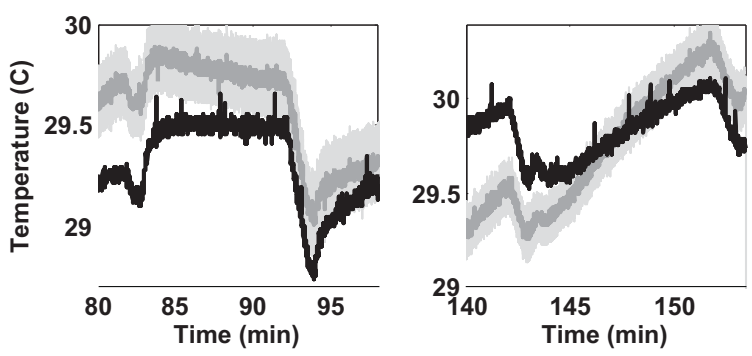

Fig. 7: Total error bounds for the $2 \mathrm{CV}$ state estimator over a) the entire calibration data set, b) the first step up in cathode air mass flow rate and c) a step down in cathode air mass flow.

At any given time step, the estimation error bounds were then considered to be the resultant maximal and minimal cathode outlet temperature estimations. These error bounds are overlaid with the $2 \mathrm{CV}$ cathode outlet estimation at nominal (measured) input conditions, as shown in Figure 7. The greatest standard deviation in the output estimation due to this noise, at any given time step, is $0.33^{\circ} \mathrm{C}$. For approximately two thirds of the experimental time, both dynamic and in steadystate, the measured cathode outlet temperature trajectory lies within the bounded output estimation. The estimation error bounds are greatest following changes in the air mass flow rate, most clearly seen at approximately 128 minutes. As expected, given that the estimator inputs for the $1 \mathrm{CV}$ and $2 \mathrm{CV}$ models are the same, the error bounds for the $1 \mathrm{CV}$ output estimation are similar to those for the $2 \mathrm{CV}$ estimation.

To investigate the influence of parameter and input values, each value was varied by the same fraction and the resultant influence on the cathode outlet temperature estimation was calculated. The sensitivity of the output estimation, $\hat{T}_{c a, \text { out }}$, to deviations in an input measurement or parameter value was determined as the percent change in the output estimation assuming all other parameters and inputs remain at nominal conditions. The sensitivity is calculated with the temperature units of ${ }^{\circ} \mathrm{C}$ as opposed to Kelvin, which significantly increases the magnitude of the sensitivity.

The maximum sensitivity of the outlet temperature estimations to $5 \%$ changes in parameter values and inputs is shown in Figure 8 a. For all $5 \%$ changes in the input and parameter values, except the cathode inlet temperature and the air mass flow rate, the cathode outlet temperature deviates by less than $1 \%$. As expected, for both models, the output estimation is most sensitive to changes in the cathode inlet temperature, $T_{c a, i n}$. In flight, the CMET could reach temperatures upwards of $49^{\circ} \mathrm{C}$. Because the cathode inlet temperature directly shifts the cathode outlet temperature estimation, the predicted cathode outlet temperature would, of course, be significantly higher than the laboratory conditions tested here. However, it is not expected that the ambient temperature would significantly influence the parameter estimation results given that the differential temperature between the bulk materials and the ambient would be approximately the same. This result indicates the importance of either directly measuring or observing the cathode inlet temperature for applications such as CMETs where the ambient temperature is not constant.

Both the $1 \mathrm{CV}$ and $2 \mathrm{CV}$ cathode outlet temperature estimators were derived assuming dry air is supplied to the cathode. Flight data recorded for the CMET during a flight in Mexico City [1] measured ambient relative humidities between $0-75 \%$. An injection of water into the cathode inlet can be accounted for by adding the enthalpy input term, $H_{w, i n}$,

$$
H_{w, i n}=\dot{m}_{v, c a, i n}\left[C_{p, l w}\left(T_{c a, i n}-T_{o}\right)+h_{f g, T_{c a, i n}}\right],
$$

to the change in enthalpy in the cathode, $\Delta H_{w, c a}$ from (19), where

$$
\dot{m}_{v, c a, i n}=\frac{\dot{m}_{a, c a, i n} M_{w} \phi_{c a, i n} p_{s a t, T_{c a, i n}}}{M_{a}\left(p_{c a, i n}-\phi_{c a, i n} p_{s a t, T_{c a, i n}}\right.},
$$

and $\phi_{c a, i n}$ is the relative humidity of the air supplied to the cathode (0-1), $p_{s a t, T_{c a, i n}}$ is the water vapor saturation pressure taken at the temperature $T_{c a, i n}(\mathrm{~Pa})$, and $p_{c a, i n}$ is the total gas pressure at the cathode inlet $(\mathrm{Pa})$. The enthalpy change associated with the air remains unchanged.

We then evaluated the impact of neglecting the cathode inlet relative humidity disturbance. By comparing the cathode outlet temperature estimation when $\phi_{c a, i n}=0$ to $\phi_{c a, i n}=0.5$, the cathode outlet temperature estimation deviated by $3 \%$. For the flight time when the cathode could receive the largest injection of water vapor from the ambient air supply [1], the water vapor still represents only $11 \%$ of the energy added to cathode from the ambient air supply. As a result, the relative humidity at the cathode inlet may not require direct measurement.

\section{OPEN LOOP OBSERVER VALIDATION}

Because the temperature observers could be deployed onboard multiple CMETs, all with the same stack materials and 


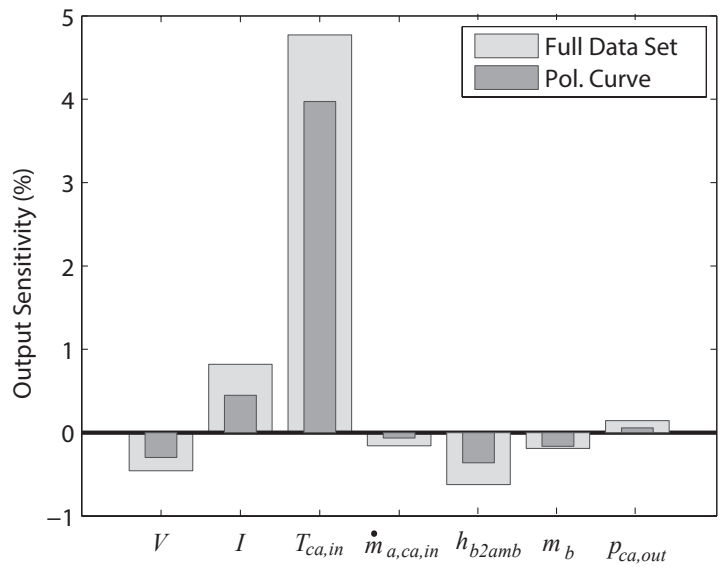

(a) One CV Model

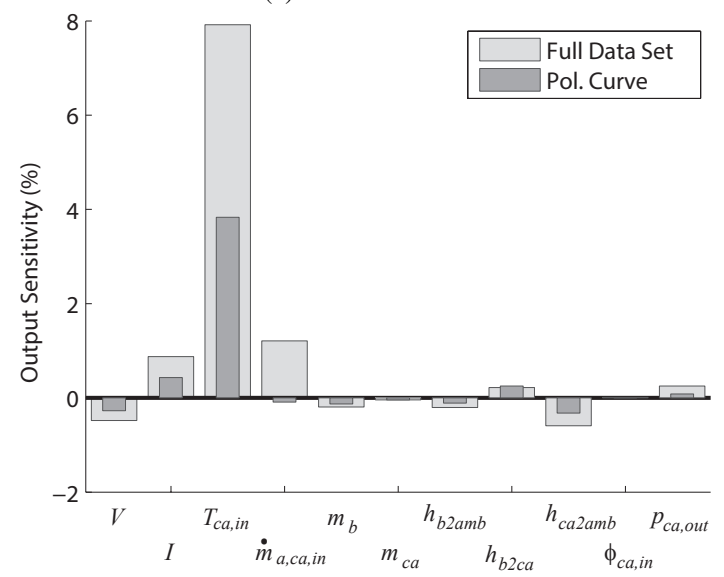

(b) Two CV Model

Fig. 8: Maximum sensitivity of cathode outlet temperature estimation to a $5 \%$ increase in the parameter or input. The maximum sensitivity was determined over two different time periods: first, over the entire dataset (wide light rectangle), then during just a load change (narrow dark rectangle).

design choices, for model validation a different fuel cell stack was constructed by replacing the original MEA and GDLs with new MEAs and GDLs. The stack was assembled with the same graphite and endplates and tested on a different date.

For validation, a similar testing protocol to that used for model calibration, described in Section IV-A, was used. However, some modifications were made. Specifically, the second polarization curve is removed and the length of time that the stack remains at constant air flow is adjusted. These changes most notably impact the temperature response between 30 70 min, shown in Figure 9. This experiment incorporates the full expected range of the control inputs. Because multiple balloons will be launched in a single campaign, experiencing similar conditions and model inputs, the ability of the designed open-loop observers to adequately estimate temperature response across multiple stacks is of interest.

The cathode outlet temperature was then estimated using the validation data inputs, with the results shown in Figure 9. The maximum difference between the measured and estimated cathode outlet temperature was $1.7^{\circ} \mathrm{C}$ with the $1 \mathrm{CV}$ model and $1.5^{\circ} \mathrm{C}$ with the $2 \mathrm{CV}$ model. The mean estimation error was $0.29^{\circ} \mathrm{C}$ with a standard deviation of $0.43^{\circ} \mathrm{C}$ for the $1 \mathrm{CV}$ model and a mean estimation error of $0.25^{\circ} \mathrm{C}$ with a standard deviation of $0.41^{\circ} \mathrm{c}$ for the $2 \mathrm{CV}$ model. These statistics exhibit a smaller estimation error and a larger standard deviation than observed for the calibration data set.
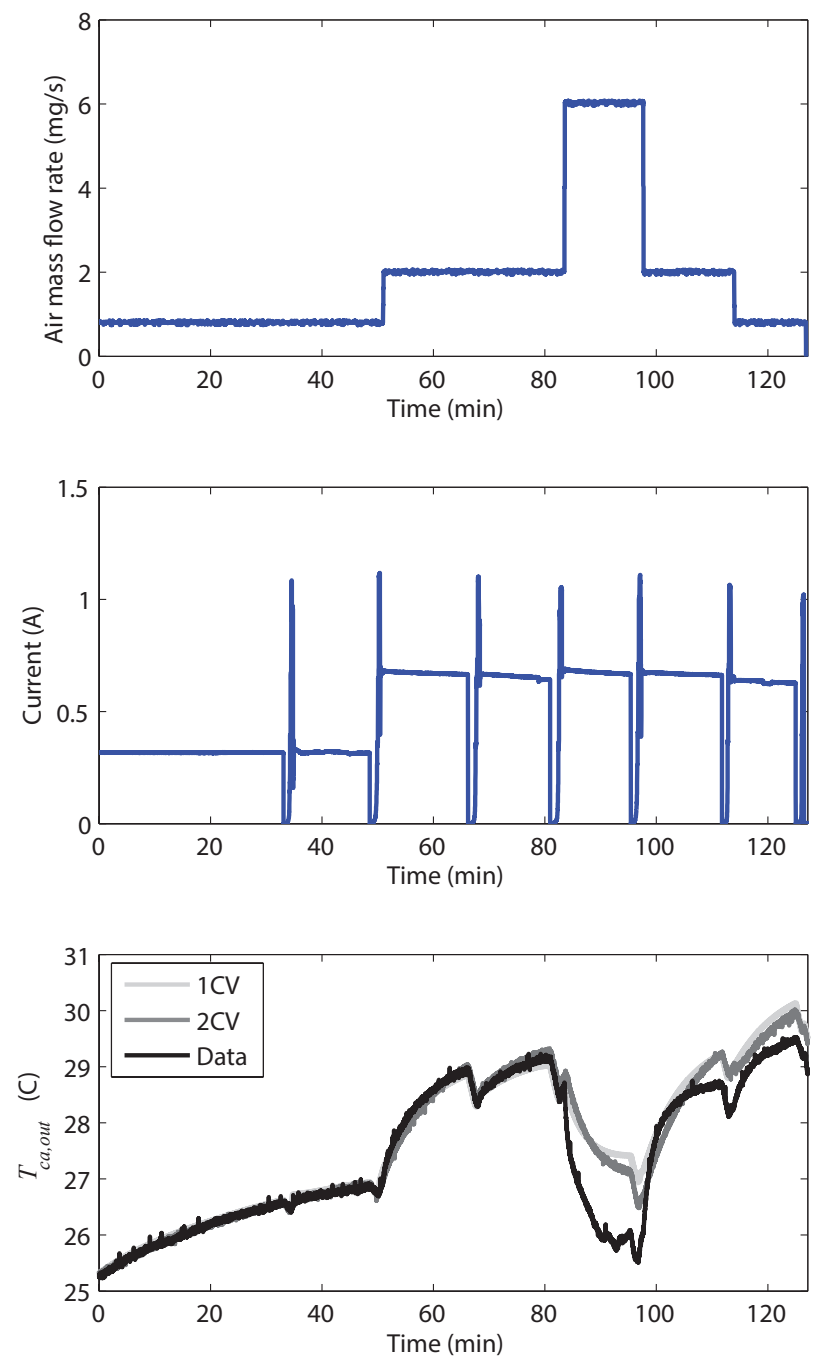

Fig. 9: Experimental validation of the $1 \mathrm{CV}$ and $2 \mathrm{CV}$ model estimated cathode outlet temperature alongside the measured data. Subplots are ordered as the measured input air mass flow rate; the measured fuel cell current disturbance; and the cathode outlet temperatures.

Throughout the experiment, both models adequately predict the cathode outlet temperature excursions following changes in load and air mass flow. Interestingly, during the first half of the data set, both the $1 \mathrm{CV}$ and $2 \mathrm{CV}$ models more accurately estimate the cathode outlet temperature than was achieved with the calibration data set. As with the calibration data, the most significant difference between the observed and estimated temperatures occurs following the second step change in air flow. By the end of the data set, the model has begun to recover to the estimated steady-state value.

The computational time of the observer models were compared using the validation data. Because the model can be simulated on different computational platforms, the resultant simulation time is less consequential than their difference in simulation time. On average, the $1 \mathrm{CV}$ model required $49.7 \%$ less time to simulate. Given that the $2 \mathrm{CV}$ model has three 
times the number of states, it is not surprising that the model requires approximately twice the simulation time.

\section{CONCLUSION}

Two models for cathode outlet temperature estimation in miniature PEMFC stacks were experimentally validated and compared. A one control volume (1 state) model can adequately estimate cathode outlet temperature when the air mass flow rate is held constant during load changes. If the PEMFC is operated at fixed air flow, or when air flow is load following, this model should be deployed due to its computational efficiency. However, if the cathode air mass flow rate will be used for active thermal management, then the higher order, two control volume (three state) model should be used. The cathode inlet relative humidity and resulting injection of water vapor into the cathode can be neglected resulting in a maximal estimation error of $11 \%$ during flight conditions. The cathode outlet temperature estimation is most sensitive to the cathode inlet (ambient) temperature, a variable that should be either directly measured or observed. These observers can be used for water and thermal management, a critical need for system optimization and control of miniature PEM fuel cell power systems.

Work is underway to incorporate a step-up DC/DC converter in this miniature fuel cell platform to reduce the PEMFC stack mass by decreasing the number of cells. Upon completion, the thermal observers developed here can be further analyzed to assess cooling needs with in-flight data. Should operation at high air mass flow rates be warranted, evaporative cooling should be re-visited. Computational energy requirements of these observers could then be quantified.

\section{REFERENCES}

[1] P. Voss, R. Zaveri, F. Flocke, H. Mao, T. Hartley, P. DeAmicis, I. Deonandan, G. Contreras-Jimenez, O. Martinez-Antonio, M. F. Estrada, D. Greenberg, T. Campos, A. Weinheimer, D. Knapp, D. Montzka, J. Crounse, P. Wennberg, E. Apel, S. Madronich, and B. Foy, "Longrange pollution transport during the MILAGRO-2006 campaign: a case study of a major mexico city outflow event using free-floating altitudecontrolled balloons," Atmos. Chem. Phys., vol. 10, pp. 7137-7159, 2010.

[2] AeroVironment, "Aerovironment flies world's first hydrogen powered plane," Fuel Cell Bulletin, vol. 9, pp. 2-3, 2005.

[3] J. Dollmayer, N. Bundschuh, and U. Carl, "Fuel mass penalty due to generators and fuel cells as energy source of the all-electric aircraft," Aerospace Science and Technology, vol. 10, pp. 686-694, 2006.

[4] L. Bohwa, K. Sejin, P. Park, and K. Kim, "Active power management system for an unmanned aerial vehicle powered by solar cells, a fuel cell, and batteries," IEEE Trans. on Aero. Electron. Sys., vol. 50, no. 4, pp. 3167-3177, October 2014.

[5] D. McKahn and W. McMackin, "Characterizing performance of a PEM fuel cell for a CMET balloon," Proceedings of the ASME 9th International Conference on Fuel Cell Science, Engineering and Technology, ESFuelCell2011-54532, Washington D.C., USA, 2011.

[6] D. McKay, J. Siegel, W. Ott, and A. Stefanopoulou, "Parameterization and prediction of temporal fuel cell voltage behavior during flooding and drying conditions." Journal of Power Sources, vol. 178, no. 1, 2008.

[7] J. Siegel, D. McKay, A. Stefanopoulou, D. Hussey, and D. Jacobson, "Measurement of liquid water accumulation in a proton exchange membrane fuel cell with dead-ended anode," Journal of the Electrochemical Society, vol. 155, no. 11, 2008.

[8] J. Siegel, S. Bohac, A. Stefanopoulou, and S. Yesilyurt, "Nitrogen front evolution in purged polymer electrolyte membrane fuel cell with deadended anode," Journal of the Electrochemical Society, vol. 157, no. 7, 2010 .
[9] D. O’Keefe, M. El-Sharkh, J. Telotte, and S. Palanki, "Temperature dynamics and control of a water-cooled fuel cell stack," Journal of Power Sources, vol. 256, pp. 470-478, 2014.

[10] J. Rojas, C. Kunusch, C. Ocampo-Martinez, and V. Puig, "Control oriented thermal modelling methodology for water-cooledpem fuel cell based systems," IEEE Trans. Ind. Elect., vol. PP, no. 99, pp. 1-1, 2015.

[11] S. Shahsavari, A. Desouza, M. Bahrami, and E. Kjeang, "Thermal analysis of air-cooled PEM fuel cells," International Journal of Hydrogen Energy, vol. 37, pp. 18 261-18 271, 2012.

[12] A. Sasmito, E. Birgersson, and A. Mujumdar, "Numerical evaluation of various thermal management strategies for polymer electrolyte fuel cell stacks," International Journal of Hydrogen Energy, vol. 36, pp. 12991$13007,2011$.

[13] E. Muller and A. Stefanopoulou, "Analysis, modeling, and validation for the thermal dynamics of a polymer electrolyte membrane fuel cell system," Journal Fuel Cell Science and Technology, vol. 3, no. 2, pp. 99-110, 2005.

[14] G. Correa, F. Borello, and M. Santarelli, "Sensitivity analysis of temperature uncertainty in an aircraft PEM fuel cell," International Journal of Hydrogen Energy, vol. 36, pp. 14745-14 758, 2011.

[15] C. Ziogou, S. Voutetakis, S. Papadopoulou, and M. Georgiadis, "Modeling, simulation and experimental validation of a PEM fuel cell system," Computers and Chemical Engineering, vol. 35, pp. 1886-1900, 2011.

[16] A. del Real, A. Arce, and C. Bordons, "Development and experimental validation of a PEM fuel cell dynamic model," Journal of Power Sources, 2007.

[17] H. Ju, C.-Y. Wang, S. Cleghorn, and U. Beuscher, "Nonisothermal modeling of polymer electrolyte fuel cells i. experimental validation," Journal of the Electrochemical Society, vol. 152, no. 8, pp. A1645A1653, 2005.

[18] D. McKahn and X. Zhao, "Channel dimensions constraints for miniature low humidity PEM fuel cells," Proceedings of 2012 ASME Fuel Cell Science and Technology Conference, ESFuelCell2012-91504, 2012.

[19] M. Ismail, D. Ingham, K. Hughes, L. Ma, and M. Pourkashanian, "Thermal modelling of the cathode in air-breathing PEM fuel cells," Applied Energy, vol. 11, pp. 529-537, 2013.

[20] Sonntag, Borgnakke, and V. Wylen, Fundamentals of Thermodynamics. John Wiley and Sons, 2003.

[21] H. Wang, W. Yang, and Y. Kim, "Analyzing in-plane temperature distribution via a micro-temperature sensor in a unit polymer electrolyte membrane fuel cell," Applied Energy, vol. 124, pp. 148-155, 2014.

[22] D. McKay, A. Stefanopoulou, and J. Cook, "A controllable membranetype humidifier for fuel cell applications, part i: operation, modeling and experimental validation," Journal of Fuel Cell Science and Technology, vol. 7, no. 4, 2010.

[23] L. Palma and P. N. Enjeti, "A modular fuel cell, modular DC-DC converter concept for high performance and enhanced reliability," IEEE Trans. on Power Electron., vol. 24, no. 6, pp. 1437-1443, 2009.

[24] M. Harfman Todorovic, L. Palma, and P. N. Enjeti, "Design of a wide input range DC-DC converter with a robust power control scheme suitable for fuel cell power conversion," IEEE Trans. Ind. Electron., vol. 55, no. 3, pp. 1247-1255, 2008.

[25] M. Mohammadi, M. Taheri, J. Milimonfared, B. Abbasi, and M. Behbahani, "High step-up dc/dc converter with ripple free input current and soft switching," IEEE Trans. Power Electron., vol. 7, no. 12, pp. 3023-3032, 2014.

Denise A. McKahn (M'09) is an Assoc. Professor at Smith College. She obtained her B.S. (2002, Humboldt State University) in Environmental Resources Engineering, M.S. (2005, University of Michigan) in Mechanical Engineering and Ph.D. in Environmental Engineering (2008, University of Michigan). She was a Research Engineer at the Schatz Energy Research Center (1998-2002). Dr. McKahn is dedicated to the development of renewable fuel and electricity generation technologies through the design, modeling and control of dynamic and complex systems.

Xinyi Liu obtained her B.S. (2014, Smith College) in Engineering and is currently a doctoral pre-candidate in the Mechanical and Aerospace Engineering department at Princeton University. Ms. Liu has focused her research on the study of renewable energy power systems, including fuel cells and batteries, and is currently studying laser-material interactions for imaging applications. 